\title{
Uganda's HIV Prevention Success: The Role of Sexual Behavior Change and the National Response. Commentary on Green et al. (2006)
}

\author{
Ronald H. Gray, ${ }^{1,5}$ David Serwadda, ${ }^{2}$ Godfrey Kigozi, ${ }^{3}$ Fred Nalugoda, ${ }^{3}$ \\ and Maria J. Wawer ${ }^{4}$
}

Published online: Apr. 25, 2006

The paper by Green et al. (vol. 10, this issue, AIDS and Behavior). on "Uganda's HIV Prevention Success" concludes that "a decline in multipartner sexual behavior" is the most likely explanation for the declines in HIV prevalence. However, this article neither addresses the inconsistencies in the available behavioral data, nor considers epidemiologic factors that may affect HIV prevalence. The latter include the fact that prevalence is a product of incidence and duration of infection (i.e., time from infection to death), and incidence is affected by infectivity per coital act that varies with the stage of disease, the number of sexual contacts, and the duration of exposures (i.e., sexual relationships). We thus consider additional factors which may have affected the history of HIV in Uganda and discuss data quality and consistency as well as epidemiologic issues.

Prior to 1989 there are no reliable populationbased data on HIV or sexual behaviors in Uganda, so the evolution of the epidemic and risk behaviors must be conjectural. Rural cohort studies in Masaka (Mulder et al., 1994) and Rakai (Serwadda et al., 1992; Wawer et al., 1991a,b, 1994), in southwestern Uganda, showed high HIV prevalence in the late 1980s and early 1990s, particularly along main roads,

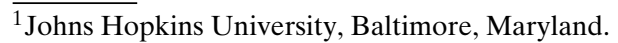

${ }^{2}$ Makerere University, Kampala, Uganda.

${ }^{3}$ Rakai Health Sciences Program, Uganda Virus Research Institute, Entebbe, Uganda.

${ }^{4}$ Columbia University, New York.

${ }^{5}$ Correspondence should be directed to Ronald H. Gray, Robertson Professor of Reproductive Epidemiology E4547, Johns Hopkins University, Bloomberg School of Public Health, 615 N Wolfe Street, Baltimore, Marlyland 21205; e-mail: rgray@jhsph.edu.
}

but moderate HIV incidence. It is reasonable to infer that there must have been high rates of HIV transmission at an earlier time point in order to explain the high observed prevalence, but that transmission had abated by the late 1980s. Modeling of the Rakai epidemic strongly suggests that there was a marked reduction in risk behaviors and HIV transmission in the mid-1980s, approximately at the end of the civil war (Korenromp et al., 2002). High HIV incidence during civil conflict might result from multiple partnerships because of social disruption and coercive sex, economic circumstances forcing women into transactional sexual relationships, and lack of condoms. A high proportion of recently infected persons would further contribute to the epidemic, given the high transmission probability per coital act observed in early infection (Wawer et al., 2005a, 2005b). The proactive policy of the Museveni administration after 1986 may have played a role in reducing high risk behaviors, but it is likely that social stabilization also contributed substantially.

In Kampala, antenatal surveillance indicated rising HIV prevalence between 1985 (the first year with available data) and 1992, and a decline thereafter, beginning approximately a decade after HIV was first recognized in Uganda (Serwadda et al., 1985). The reported change in prevalence in Kampala was particularly pronounced between 1993 and 1994. Declines were also noted in other urban and rural antenatal surveillance sites (Hogle, 2002; Stoneburner and Low-Beer, 2004), and in population-based cohort studies, albeit at a much more gradual rate. The declines in prevalence can be attributed, in part, to an excess of mortality among persons infected on av- 
erage 9-10 years earlier, relative to the rates of new infections occurring in 1990s (Morgan et al., 2002; Wawer et al., 1997).

The decline in HIV prevalence in young pregnant women does suggest a reduction of incident infections at younger ages, potentially as a consequence of reduced risk behaviors (Stoneburner and Low-Beer, 2004). However, care must be taken in interpreting the data. First, the rate of decline in prevalence reported between 1993 and approximately 1995 (Stoneburner and Low-Beer, 2004) was so rapid that even if incidence in young women had fallen to zero, this could not account for the dramatic change. For example, antenatal data from Kampala suggest a $30 \%$ reduction in HIV prevalence (from 28 to $19 \%$ ) over a single year [1993-1994]. This suggests either a substantial and short-lived spike of mortality among young HIV-infected women of reproductive age (an unlikely occurrence), or more probably, a change in surveillance procedures. Although the preponderance of the Ugandan data indicates that HIV prevalence has genuinely declined, changes in surveillance and reporting would complicate the determination of the timing and speed of the reduction.

Second, the data on behavior change during the 1990s are contradictory. Several authors have used sequential Demographic and Health Surveys (DHS) to conclude that there were delays in the age of sexual debut and declines in multiple partnerships among younger persons (Blum, 2004; Hogle, 2002; Stoneburner and Low-Beer, 2004). However, comparisons between DHS surveys are problematic because their population coverage varied over time, with whole districts excluded in some surveys, and with different aggregations of districts used in the survey analyses (Kaijuka et al., 1989; Statistics Department Uganda, 1996; Uganda Bureau of Statistics ORC Macro, 2001). There are considerable regional differences in key behaviors, so the geographic variations in the DHS can seriously confound analyses of time trends. To avoid such confounding, DHS has analyzed age-specific rates within the 1995 and 2000-2001 surveys (i.e., holding coverage constant and assessing behaviors over time by comparing behaviors reported by younger and older women). The within-survey DHS analyses indicate no changes over time in the reported age of sexual debut, age at first marriage, age at first birth or the number of nonmarital partners (Statistics Department Uganda, 1996; Uganda Bureau of Statistics ORC Macro, 2001). Other smaller surveys suffer from similar problems of inconsistent sample coverage. Although DHS surveys suggest substantial increases in condom use, particularly with nonmarital partners, intersurvey comparisons could also be problematic. However, among respondents in the 2000-2001 DHS survey, a substantially higher proportion of sexually active young women (29 and under) reported ever using condoms, compared to older women, suggesting a substantial increase in condom use in the 1990s (Uganda Bureau of Statistics ORC Macro, 2001). These data, along with longitudinal cohort data (Wawer et al., 2005b) and the growing number of condoms distributed in Uganda; USAID provided 4 million in 1990, 16 million in 1994, and 34 million are on order for 2006 (Marum, 1995; Mogwanja, 2005), suggest that condom use has increased substantially. In summary, although HIV prevalence declined in 1990s, we cannot disaggregate the contributions of specific behavioral change (abstinence, monogamy, condom use), postwar social stabilization, the direct effects of government prevention programs, and the natural evolution of the epidemic (i.e., declines in prevalence due to mortality exceeding incidence, and declines in transmission as fewer people were in the early, highly infectious, stages of disease).

More important than a speculative debate on what happened in the past is the question of what appears to be happening in recent years. Antenatal surveillance data suggest that national HIV prevalence in pregnant women has stabilized at around $6 \%$, the 2004-2005 serosurvey reported an HIV prevalence of $6.5 \%$, but found no age-specific trends in the reported age at first sex (Ministry of Health, 2005). In a recent Ministry of Health meeting in November 2005, preliminary data were presented, on the basis of antenatal surveillance conducted in 2005, which suggest that HIV seroprevalence in some parts of Uganda may be increasing. Longitudinal studies in Rakai from 1994 to 2003 suggest declines in HIV prevalence, but stable HIV incidence. In Rakai, the age of first sex reported by boys declined significantly, but the number of nonmarital partners reported by adolescents and young adults increased in both sexes (Wawer et al., 2005b) and these data are consistent with findings from the 2004 to 2005 national serosurvey (Ministry of Health, 2005). Concurrently, condom use in Rakai increased substantially, particularly among those reporting nonmarital partners (Wawer et al., 2005b). The inconsistent behavioral changes in Rakai (some 
risk behaviors declined whereas other increased) occurred despite the National Program's ongoing emphasis on abstinence and fidelity (A, B), the Rakai Program's intensive risk reduction education (A, B, and C), and very high levels of VCT acceptance in the Rakai population. The behavioral trends in Rakai may partly reflect "prevention fatigue" or a growing complacency among younger people who have less personal experience with the disease. Furthermore, the availability of antiretroviral therapy might exacerbate behavioral disinhibition as a result of "treatment optimism," as has been observed in United State and Europe (Crepaz et al., 2004).

Thus, the key question today is whether we can reduce risk behaviors to avoid a resurgence of HIV transmission. This requires a balanced program to encourage premarital abstinence, marital fidelity and consistent condom use. In Uganda, recent media campaigns have questioned the effectiveness of condoms, and there was a national shortage of condoms in 2004-2005 (Mogwanja, 2005; Human Rights Watch, 2005). Along with A and B, condoms are an integral part of HIV prevention. Countries do a dis-service to their populations by denigrating this method of prevention or not ensuring access, and Shelton and Johnson (2001) have drawn attention to the widening "condom gap" in Africa.

The debates about the history of the HIV epidemic in Uganda, while of academic interest, fail to address the dilemmas facing policy makers today. Unless prevention programs can reduce HIV incidence, the burden of treatment will grow and exceed the resources available. Thus progress in Uganda during the 1990s might prove to be a Pyrrhic victory in the long war on HIV/ AIDS.

\section{REFERENCES}

Blum R. (2004). Uganda AIDS prevention: A, B, C and politics. Journal of Adolescent Health, 34, 428432.

Crepaz, N., Hart, T. A., and Marks, G. (2004). Highly active antiretroviral therapy and sexual risk behavior. A meta-analytic review. JAMA, 292, 224-236.

Green, E. C., Halperin, D., Nantulya, V., and Hogle, J. A. (this issue). Uganda's HIV Prevention Success: The role of sexual behavior change and the National Response. AIDS and Behavior, 10, XXX-XXX.

Hogle, J. A. (2002). What happened in Uganda? Declining $H I V$ prevalence, behavior change and the national response. Washington, DC: USAID Synergy Project.

Human Rights Watch (2005). The less they know, the better. Abstinence-only HIV? AIDS Programs in Uganda, 17, 1-79.
Kaijuka, E. M., Kaija, E. Z. A., Cross, A. R., and Loaiza, E. (1989). Demographic and Health Survey 1988/1989. Ministry of Health, Entebbe, Uganda in collaboration with Ministry of Planning and Economic Development, Institute of Statistics and Applied Economic, Makerere University and Institute for Resource development/Macro Systems, Inc. Columbia, MD.

Korenromp, E. L., Bakker, R., Gray, R., Wawer, M. J., Serwadda, D., and Habbema, J. D. (2002). HIV dynamics and behaviour change as determinants of the impact of sexually transmitted disease treatment on HIV transmission in the context of the Rakai trial AIDS. Sexually Transmitted Infections, 16, 22092218.

Marum, E. (1995). The AIDS epidemic in Uganda and the US Government Response. Kampala, Uganda: USAID.

Mogwanja, M. (2005). Statement by Chair of the United Nations Theme Group on HIV/AIDS: The condom shortage in Uganda. Available from Ron Gray, Johns Hopkins University, MD (rgray@jhsph.edu).

Morgan, D., Mahe, C., Mayanja, B., Okongo, J. M., Lubega, R., and Whitworth, J. (2002). HIV-1 infection in rural Africa: Is there a difference in median time to AIDS and survival compared with that in industrialized countries? AIDS, 16, 597603.

Mulder, D. W., Nunn, A. J., Wagner, H. A., Kamali, A., KangeyaKayondo, J. F. (1994). HIV-1 incidence and HIV-1-associated mortality in a rural Ugandan population cohort. AIDS, 8, 8792.

Ministry of Health, Uganda, Measure DHS, ORC Macro, Centers for Disease Control and Prevention. (2005). Uganda HIV/AIDS Sero-behavioral Survey 2004-2005, Preliminary Report. Ministry of Health, Kampala, Uganda.

Serwadda, D., Mugerwa, R. D., Sewankambo, N. K., Lwegaba, A., Carswell, J. W., Kirya, G. B., Bayley, A. C., Downing, R. G., Tedder, R. S., and Clayden, S. A. (1985). Slim disease: A new disease in Uganda and its association with HTLV-III infection. Lancet 2(8460), 849-52.

Serwadda, D., Wawer, M. J., Musgrave, S. D., Sewankambo, N. K., Kaplan, J. E., and Gray, R. (1992). HIV risk factors in three geographic strata of rural Rakai District, Uganda. AIDS, 6 , 983-989.

Shelton, J. D., and Johnson, B. (2001). Condom gap in Africa: Evidence from donor agencies and key informants. British Medical Journal, 323, 139.

Statistics Department (Uganda) and Macro International Inc (1995). Uganda Demographic and Health Survey. Maryland: Calverton.

Stoneburner, R., and Low-Beer, B. (2004). Population-level HIV declines and behavioral risk avoidance in Uganda. Science, 304, 714-785.

Uganda Bureau of Statistics ORC Macro (2001). Uganda Demographic and Health Survey 2000-2001. MD: Calverton.

UNAIDS/WHO (1998). A measure of success in Uganda: The value of monitoring both HIV prevalence and sexual behaviour. Geneva: UNAID/WHO.

Wawer, M. J., Serwdaa, D., Musgrave, S. D., Konde-Lule, J. K., Musagara, M., and Sewankambo, N. K. (1991a). Dynamics of spread of HIV-1 infection in a rural district of Uganda. British Medical Journal, 303, 1303-1306.

Wawer, M. J., Sewnakambo, N. K., Berkley, S., Serwadda, D., Musgrave, S. D., Gray, R. H., Musugara, M., Stallings, R.Y., Konde-Lule, J. K. (1991b). Incidence of HIV-1 infection in a rural region of Uganda. British Medical Journal, 308, 171173.

Wawer, M. J., Serwadda, D., Gray, R. H., Sewankambo, N. Li. , Nalugoda, C., Lutalo, T., and Konde-Lule, J. (1997). Trends in HIV-1 prevalence may not reflect trends in incidence in mature epidemics: Data from the Rakai population-based cohort, Uganda, AIDS, 11, 1023-1030. 
Wawer, M. J., Gray, R. H., Serwadda, D., Namukwaya, Z., Makumbi, F., Sewankambo, N., Li, X., Lutalo, T., Nalugoda, F., and Quinn, T. (2005a). Declines in HIV prevalence in Rakai, Uganda: Not as simple as ABC. Late Breaker Oral, Abstract \#27LB, 12th Conference on Retroviruses and Opportunistic Infections, Boston, Feb 22-25, 2005.
Wawer, M. J., Gray, R. H., Sewankambo, N. K., Serwadda, D., Li, X., Laeyendecker, O., Kiwanuka, N., Kigozi, G., Kiddugavu, M., Lutalo, T., Nalugoda, F., Wabwire-Mangen, F., Meehan, M. P., and Quinn, T. C. (2005b). Rates of HIV-1 Transmission per Coital Act, by Stage of HIV-1 Infection, in Rakai, Uganda. Journal of Infectious Diseases, 191, 1403-1409. 